\title{
Affection Substitution: The Effect of Pornography Consumption on Close Relationships
}

\author{
Colin Hesse \\ Kory Floyd \\ Oregon State University \\ University of Arizona
}

In press: Journal of Social and Personal Relationships

Note. Colin Hesse is an associate professor of communication studies at Oregon State University.

Kory Floyd is a professor of communication at the University of Arizona. Correspondence to Colin Hesse at colin.hesse@oregonstate.edu 


\begin{abstract}
Scholars have long believed in the fundamental axiom that humans have a fundamental need to belong. However, less is known about the possibility of substitution: whether individuals can use other resources to substitute for close relationships. In the current study, 357 adults reported on their level of affection deprivation, their weekly pornography consumption, their goals for using pornography, and indicators of their individual and relational wellness. As predicted, affection deprivation and pornography consumption were inversely related to relational outcomes such as satisfaction and closeness, and affection deprivation was positively correlated with most stated goals for pornography use. More important, pornography consumption moderated the association between affection deprivation and depression, such that using pornography more frequently made the relationship between affection deprivation and depression stronger. This effect was independent of participants' stated goals for using pornography. Considered collectively, the results suggest that people do use pornography as a coping mechanism for dealing with affection deprivation, but that doing so is largely maladaptive, at least with respect to depression.
\end{abstract}

Keywords: Affection, Pornography Consumption, Need to Belong 


\section{Affection Substitution: The Effect of Pornography Consumption on Close Relationships}

Scholars in the social sciences have built an impressive body of research supporting the axiom that humans have a fundamental need to belong (Baumeister \& Leary, 1995). According to this premise, humans are driven to build and maintain a minimum number of close, committed relationships, which allow us to access more resources that increase our chances for survival. In the communication literature, affection exchange theory (AET: Floyd, 2006) proposes that we meet this need partially by the exchange of affectionate behavior, and that affection helps us build and maintain those close, committed relationships. Decades of research support that prediction by demonstrating that the exchange of affectionate behavior corresponds with benefits at the psychological, physical, and relational levels (e.g., Floyd, 2002; Floyd \& Riforgiate, 2008; Hesse \& Floyd, 2011).

In the literature surrounding the need to belong, one question concerns the possibility of substitution, or whether humans can use other forms of connection to fulfill the need to belong when close, committed relationships are absent. For example, military personnel can form close relationships with fellow soldiers to substitute for close relationships who are not deployed with them (Setterstren, 2006). Similarly, relational deprivation associated with incarceration can motivate the formation of ersatz sexual relationships - typically homosexual in nature due to sex segretation — among prisoners as a substitute for long-term intimacy (see Hensley, Tewksbury, \& Wright, 2001). Substitution can also be sought outside of real relationships. The literature on parasocial relationships deals with the propensity to form a connection with fictional characters in media, and elements like parasocial breakups can lead to emotional consequences (e.g., Cohen, 2004; Rubin \& McHugh, 1987). These avenues for substitution have not always been 
adaptive, with one study finding a positive correlation between parasocial relationships and loneliness (Baek, Bae, \& Jang, 2013). However, one communication study found that although forming parasocial relationships exacerbated loneliness for men, it reduced loneliness for women (Wang, Fink, \& Cai, 2008).

The current study examines this question of substitution using the context of pornography consumption. Pornography consumption is relatively standard in the present day, especially for young adult populations (Flood, 2007). We propose that watching pornography can serve a substitution function, wherein individuals attempting to meet deficient inclusion needs using media. Thus, we expect that consumption will be linked with a deprivation of belongingness (specifically, of affection), and that affection can help explain some of the relationships between pornography consumption and personal wellness. To address this question, we overview some of the research on the benefits of affectionate behavior contrasted with the consequences of affection deprivation. We then look at how individuals might cope with affection deprivation and identify pornography consumption as one substitution tactic.

\section{Benefits of Affectionate Behavior}

AET (Floyd, 2006) states that the need for human affection is innate across time and culture. This is due to affection helping us fulfill our need to belong, thus serving the two ultimate evolutionary goals of survival and reproduction. Specifically, AET predicts that affection serves those goals by allowing individuals to access more resources and showing potential partners that they would be a fit parent (Floyd, 2006). The exchange of affection in close relationships is thus beneficial, and AET predicts that sharing affection is associated with physical, psychological, and relational benefits. 
A growing body of research supports this prediction, with previous studies examining all three types of benefits. Physically, there is an inverse correlation between trait affection (one's typical "set point" of affection expressed to others) and cardiovascular and metabolic indices of arousal, including resting heart rate, blood pressure, and glycosylated hemoglobin (Floyd, Hesse, \& Haynes, 2007). Marital partners who reported receiving higher levels of affection from their spouse evidence greater diurnal variation in cortisol levels, a sign of reduced physical stress (Floyd \& Riforgiate, 2008). In another study, participants with higher levels of both trait and state affection experienced greater increases in oxytocin during a series of stress-inducing tasks, demonstrating the stress-buffering qualities of affection (Floyd, Pauley, \& Hesse, 2010). Overall, these studies show that affection, whether experienced as a general trait or in a specific relationship, corresponds to lower degrees of physiological stress.

The connections between affection and both mental and relational health are also strong. Over several studies, affection is inversely correlated with mental health problems such as depression, loneliness, stress, and general mental health (e.g., Floyd, 2002; Floyd, Hess, et al., 2005; Hesse \& Floyd, 2008; Mansson, 2013). In the same vein, affection is positively correlated with a host of positive relational variables, including relational satisfaction, relational closeness, relational commitment, the drive for intimacy, and the number of close relationships (e.g., Floyd, 2002; Floyd, Boren, et al., 2009; Hesse \& Floyd, 2011; Horan \& Booth-Butterfield, 2010). Individuals who give and receive more affection appear to be advantaged in both their mental health and their ability to develop and maintain close relationships. In general, this research supports the general claims of both AET and the need to belong perspective that people need relationships, that affection is a tool by which we build and maintain them, and that affection is therefore beneficial to individual and relational well-being. 


\section{Consequences of Affection Deprivation}

A sufficient level of affectionate behavior is required to procure individual and relational benefits, however, and AET predicts that a deficit in one's desired level of affection is not only unhelpful but aversive. Specifically, AET's fourth postulate claims that humans vary in their optimal tolerances for affectionate behavior, implying that receiving both too much affection and too little are problematic. In the affection literature, the state in which an individual routinely receives less affection than he or she needs or desires is known as affection deprivation (Floyd, 2016). Research indicates that affection-deprived children experience cognitive delays (Beckett et al., 2006) and have a higher propensity for eating disorders (Gupta, Gupta, Schork, \& Watteel, 1995). In his initial study on the deprivation of affectionate touch, Floyd (2014) found positive correlations between touch deprivation and loneliness, depression, stress, and insecure attachment. Future studies expanded this concept to a general perception of deprivation, finding positive correlations between deprivation and chronic pain, poor-quality sleep, and loneliness once again (Floyd, 2016; Floyd \& Hesse, 2017). These three studies show a strong potential relationship between deprivation and mental and physical health.

Two additional studies have examined the relational consequences of deprivation. First, Hesse and Mikkelson (2017) probed affection deprivation within the context of close relationships, defining deprivation as receiving less affection than desired from one's relational partner, specifically. That study found inverse correlations between relational deprivation and relational satisfaction, relational closeness, and relational commitment, with a positive correlation between deprivation and relational uncertainty. Second, affection deprivation can be problematic even in relationships that are not supposed to be particularly close. One study took the concept into the doctor-patient realm, finding inverse correlations between perceived 
affection deprivation that the patient experienced from the doctor and variables such as patient satisfaction, patient adherence, and perceived doctor communication competence (Hesse \& Rauscher, 2018). Combined with the previous studies showing correlations with insecure attachment, these studies support the prediction that affection deprivation is unhealthy for an individual, and that this effect manifests in terms of both mental and relational wellness.

\section{Coping with Affection Deprivation}

Deprivation of an important resource frequently prompts compensatory coping strategies (Carver, Scheier, \& Weintraub, 1989). AET's subpostulate 5a indicates that when people receive too little affection, they consider that state to be a challenge to their survival and well-being, which ought to prompt coping strategies aimed at creating or restoring a desired state of interpersonal connection. Some potential coping strategies for affection deprivation can be ascertained by examining research on how individuals cope with a similar state, loneliness. Whereas affection deprivation implies a deficit in the receipt and exchange of affectionate behavior, loneliness is a broader state characterized by a deficit in one's desired level of social contact (Cacioppo \& Patrick, 2008). Although they are distinct phenomena (Floyd \& Hesse, 2017), loneliness and affection deprivation share enough conceptual and empirical space that coping strategies for the former can inform those of the latter.

Coping strategies for loneliness run the spectrum from those that are helpful (or, at least, benign) to those that are highly maladaptive. Some strategies focus on generating — or at least simulating — contact. For instance, keeping a pet can provide opportunities for touch and loving interaction that can reduce feelings of loneliness (Rew, 2000). Some find that confiding in a psychotherapist, counselor, physician, or pastor provides both a helpful perspective on loneliness and an opportunity for interpersonal connection (Rokach, 1990). Reaching out to one's social 
network and trying to reestablish latent connections can help (Rook, 1984). Still other individuals cope with loneliness by engaging in casual, sometimes illicit sexual "hook-ups," which provide the opportunity for at least temporary intimate human contact (see Levinson, Jaccard, \& Beamer, 1995).

A second category of coping strategies focuses on those that increase one's sense of empowerment or control over their own or others' lives. For instance, eating disorders such as anorexia nervosa, bulimia nervosa, and binge eating disorder can provide sufferers with a sense of personal control (Waller, 1998), and conditions such as bulimia and binge eating disorder can additionally simulate a sense of emotional connection (Cacioppo \& Patrick, 2008; see also Grant, 2008), making it unsurprising that these conditions are comorbid with loneliness (Levine, 2012). Bullying others (Nansel et al., 2001) and engaging in criminal activity (Rokach, 1990) are both associated with loneliness and can provide perpetrators with a feeling of empowerment. Extreme loneliness and despair even shows strong associations with suicide ideation (Stravynski \& Boyer, 2001) and suicide attempts (Wiktorsson, Runeson, Skoog, Östling, \& Waern, 2010), which might be considered ultimate acts of control over one's own life.

Still other strategies attempt to cope with loneliness by prompting temporary elevations in dopamine, a catecholamine implicated in the sensation of pleasure and reward (Schultz, 2015). Besides providing intimate contact, casual sexual behavior can also prompt dopamine reward (Krüger, Hartmann, \& Schedlowski, 2005). In addition, dopaminergic activity is implicated in addictive behaviors, such as drug and alcohol addiction (Di Chiara et al., 2004) and pathological gambling (Blaszczynski, \& Nower, 2002), and both behaviors are comorbid with loneliness (Åkerlind \& Hörnquist, 1992; Dowling \& Brown, 2010). 
This accounting of coping strategies for loneliness is certainly not exhaustive, but it does implicate specific motivations - increasing or simulating interpersonal contact, gaining empowerment, and provoking dopamine reward — that may also be operative in individuals' attempts to cope with a deficit in affection. No study prior to the current investigation has explored specific coping strategies for affection deprivation. As the subsequent section describes, this study proposes that the consumption of pornography may be a common coping strategy because of its potential to simulate intimacy and dopaminergic reward, whether its ultimate effect on the outcomes of affection deprivation is adaptive or maladaptive.

\section{Pornography Consumption as a Coping Strategy}

Compared to the coping strategies delineated above for loneliness, a lesser-understood potential strategy for dealing with a lack of social connection is the consumption of pornography. Especially among younger adults and adolescents, pornography consumption is relatively common, and particularly so for men. In a survey of college students, Carroll et al. (2008) found that $87 \%$ of men and $31 \%$ of women reported using pornography in some form. A later study of college students by Willoughby, Carroll, Nelson, and Padilla-Walker (2014) found that 75\% of men and $19 \%$ of women had used pornography within the previous 12 months, with $6 \%$ of men and $1 \%$ of women reporting daily use (see also Boies, 2002; Wolak, Mitchell, \& Finkelhor, 2007).

Several problems have been associated with the consumption of pornography (especially Internet pornography), including decreased sexual desire for one's romantic partner (Carvalheira, Træen, \& Stulhofer, 2015), emotional problems (Philaretou, Mahfouz, \& Allen, 2005), and the generation of unrealistic sexual expectations (Sun, Bridges, Johnson, \& Ezzell, 2016). Although pornography consumption is not necessarily pathological, a preoccupation with pornography is a 
risk factor for psychopathologies such as hypersexual disorder (Stein, Black, Shapira, \& Spitzer, 2001). Other studies have instead documented benefits to pornography consumption, including increased stress relief, decreased boredom, and increased sexual knowledge (Cooper, Galbreath, \& Becker, 2004; Hald \& Malamuth, 2007).

Research has established that both loneliness and affection deprivation are correlated with pornography consumption. Yoder, Virden, and Amin (2005), for instance, found that the number of minutes spent per week looking at Internet pornography was significantly associated $(\beta=.35)$ with loneliness (see also McBride, Reece, \& Sanders, 2007; Twohig, Crosby, \& Cox, 2009). Similarly, Hesse (2016) reported a moderate relationship between affection deprivation and the number of days per week that participants consumed pornography $(\beta=.44)$. On the basis of these associations, one certainly might speculate that pornography use is a consequence of social disconnection, and/or a cause of further disconnection, but the present study explores pornography use as a deliberate coping strategy for feeling deprived of interpersonal affection.

No prior research has examined pornography consumption as a coping strategy for social disconnection, but there are reasons to suspect that it may serve this function. For one, it engages the fantasy of intimate human contact, which may stimulate the sensation of belonging (Baumeister \& Leary, 1995) and may even prompt the perception of having formed parasocial relationships (Giles, 2002), as also occurs in the consumption of romance novels (Burnett \& Beto, 2000). Second, when accompanied by masturbation to sexual orgasm, it is associated with the release of reward-imparting hormones such as dopamine (Krüger et al., 2005), prolactin (Krüger, Haake, Hartmann, Schedlowski, \& Exton, 2002), and oxytocin (Carmichael et al., 1987). As such, pornography consumption may provide both a sense of human contact and a 
self-soothing physiological pleasure sensation that make it a common coping strategy for social disconnection, whether its ultimate utility as a coping mechanism is adaptive or maladaptive.

\section{Hypotheses}

Based on these arguments, the current study addresses two goals. The first goal is to further verify associations between affection deprivation and outcomes related to personal relationships and mental wellness. On the basis of AET's claim that affectionate communication contributes to individual and relational well-being and stability, we propose that exchanging affection is beneficial for the satisfaction and closeness of personal relationships and detrimental to experiences of loneliness and depression, whereas being deprived of the amount of affection one desires shows opposite patterns. Stated as formal hypotheses:

Hypothesis 1: Experienced affection is positively related to a) relational satisfaction and b) closeness; and inversely related to c) loneliness and d) depression.

Hypothesis 2: Affection deprivation is inversely related to a) relational satisfaction and b) closeness; and positively related to c) loneliness and d) depression.

The second goal of the current study is to identify associations between pornography consumption, affection deprivation, and relational and mental wellness. First proposed is that affection and affection deprivation are associated with the practice of consuming pornography:

Hypothesis 3: Pornography consumption is a) positively related to affection deprivation and b) inversely related to experienced affection.

Extending previous empirical findings, we also predict that the use of pornography is associated with relational and mental well-being:

Hypothesis 4: Pornography consumption is inversely related to a) relational satisfaction and b) closeness; and positively related to c) loneliness and d) depression. 
Next, if pornography consumption is used as a coping strategy for affection deprivation, then it is logical to presume that people report consuming pornography for goals that are specifically related to social disconnection. In particular, pornography may serve the functions of reducing loneliness and building parasocial relationships by simulating intimate human contact (Giles, 2002), and may also prompt a sense of fantasy or escape from one's affection-deprived state (see Malamuth \& Billings, 1986). This hypothesis relates not to how often people consume pornography, but to why they consume it:

Hypothesis 5: Affection deprivation is positively related to the tendency to use pornography for the purposes of a) reducing loneliness, b) finding escape, and c) building parasocial relationships.

As a research question, we also ask whether affection deprivation relates to the tendency to use pornography for other specific purposes unrelated to alleviating social disconnection, which may include contributing to life satisfaction and achieving sexual gratification (see Löfgren-Mårtenson \& Månsson, 2009):

RQ1: How, if at all, is affection deprivation related to the tendency to use pornography for the purposes of a) improving life satisfaction, and b) achieving sexual gratification. Finally, if individuals use pornography as a way to cope with affection deprivation, it is logical to predict that pornography usage moderates the associations between deprivation and indices of individual and relational well-being. It is also possible that one's stated goals for consuming pornography make a difference in its effects on well-being (namely, whether some reasons lessen the negative influence of pornography on well-being). Thus, we propose H6 and RQ2:

Hypothesis 6: Pornography consumption moderates the relationships between affection 
deprivation and relational (satisfaction and closeness) and mental (loneliness and depression) well-being.

RQ2: How, if at all, do the reasons for consuming pornography influence the relationships between pornography consumption and relational and mental well-being?

\section{Method}

\section{Participants}

There were 357 participants in the current study, including 162 males and 192 females (1 participant marked "other" for gender and 2 participants declined to answer the question). Participants ranged in age from 20 to 73 years old, with a mean of 38.73 years $(S D=10.27)$. Participants self-identified as white/Caucasian (82\%), Asian American (8\%), African American (6\%), Hispanic (4\%), and Native American (1\%), with one participant indicating "other" (percentages sum to $>100$ because some participants identified more than one ethnicity). In terms of household income, roughly half of the participants $(56 \%)$ reported an income lower than $\$ 50,000$, with only $8 \%$ reporting an income greater than $\$ 100,000$. Most participants reported themselves as either in a dating (34\%) or marital (55\%) relationship, with the rest reporting themselves as divorced $(10 \%)$ or widowed (1\%) (participants in the final two categories still had to be in a current dating relationship to qualify for the study). A power analysis indicated that an $N$ of 357 provided in excess of $90 \%$ power to detect small to medium effect sizes, assuming a .05 error rate.

\section{Procedures}

Participants were recruited via the Amazon.com crowdsourcing marketplace Mechanical Turk (MTurk). To be eligible for the study, participants had to have attained the age of majority in their state, be in a current romantic relationship, be located in a U.S. state or territory, be able 
to read and write English, and be a "master worker" (a designation indicating consistently high quality in submitted work) who had completed at least five previous jobs with an average approval rate equaling or exceeding 90\%. Eligible participants completed and submitted an online questionnaire in exchange for $\$ 1.50 \mathrm{US}$. Research has found that samples recruited on MTurk for academic research are typically more representative of the U.S. population than are in-person convenience samples (Berinsky, Huber, \& Lenz, 2012; Buhrmester, Kwang, \& Gosling, 2011; Paolacci, Chandler, \& Ipeirotis, 2010). Upon recruitment, participants were directed to a Qualtrics survey. The first page of the study included the explanation of research document as well as two questions confirming the inclusion criteria of age and relational status (participants were removed from the survey at this point if they did not qualify for the study). Once participants completed the survey, they entered a code on the MTurk website, receiving \$2.00US. The study was funded internally and was completed following IRB approval at both authors' institutions.

\section{Measures}

All measures except for pornography consumption consisted of 7-point Likert-type scales where higher scores reflected greater intensity of the variable. Internal reliability estimates, means, standard deviations, and intercorrelations for all measures can be found in Table 1.

Experienced affection. The experienced affection scale was created by combining the 10-item trait given affection scale (TAS-G) and the 6-item trait received affection scale (TAS-R) created by Floyd (2002). This combination has been done in several previous studies where the distinction between given and received affection is unimportant to the research question (e.g., Hesse \& Floyd, 2008; 2011). Thus, scale items included both, "Many people I know are quite affectionate with me," and, "I consider myself to be a very affectionate person." 
Affection deprivation. Affection deprivation was measured using the 8-item revised scale created by Floyd (2016). This revision moved the deprivation scale to a more general perception of deprivation (instead of being focused on touch), while adding two more items to the study. Scale items included, "I don't get enough affection from others," and, "Affection is something I could use more of in my life."

Pornography consumption. Pornography consumption was assesed using a single-item measure, “On average, how many days per week do you consume pornography?" Answers could range from $0-7$. This method of assessing pornography consumption has been used in several previous studies looking at the relationships between consumption and relational/mental wellbeing (e.g., Yoder, Virden, \& Amin, 2005).

Relational satisfaction. Relationship satisfaction was measured using the 7-item Relationship Assessment Scale developed by Hendrick (1988). Scale items include, "In general, how satisfied are you with your relationship?" and "To what extent has your relationship met your original expectations?"

Relational closeness. Relationship closeness was measured using the single-item Inclusion of Other in the Self measure (Aron, Aron, \& Smollan, 1992). The item consists of several pictures of two circles that show various amounts of overlap ranging from none to complete. Participants were asked to check the number associated with the picture that best described their romantic relationship.

Loneliness. Loneliness was measured using the 20-item UCLA Loneliness Scale (Version 3: Russell, 1996). Participants were asked to report how often they felt aspects like, "you lack companionship," "there is no one you can turn to," and, "no one really knows you well?" 
Depression. Depression was measured by the 21-item Beck Depression Inventory II (Beck, Steer, \& Garbin, 1998). Participants self-report on how often they experienced certain things like feelings of sadness and pessimism or experiencing tiredness or anti-social thoughts.

Reasons for consuming pornography. Based on a review of literature related to the functions of pornography (e.g., Attwood, 2005; Löfgren-Mårtenson \& Månsson, 2009;

Malamuth \& Billings, 1986; Paul \& Shim, 2008), the authors generated a list of 19 items related to several possible reasons why individuals would consume pornography, and subjected the items to a principal components exploratory factor analysis with oblique rotation $(\mathrm{KMO}=.89$, Bartlett's test of sphericity $\left.\chi^{2}=2522.72, d f=171, p<.001\right)$. Four factors had eigenvalues exceeding 1 but a Scree plot indicated that a five-factor solution, accounting for $75.80 \%$ of the total variance, was also viable. The first factor included items related to the formation of parasocial relationships with pornography actors (e.g., "I feel like I am interacting with the people in the images or video"). The second factor related to sexual gratification (e.g., "I use porn to sexually arouse myself'). The third factor related to finding escape from one's situation (e.g., "Watching porn makes me forget problems I have in my life"). The fourth factor related to feeling more satisfied with life (e.g., "I feel more satisfied with my life when I watch porn"). The final factor related to the ability to reduce feelings of loneliness (e.g., "Looking at porn makes me feel less lonely").

\section{Results}

\section{Descriptive Statistics}

Before running our hypothesis tests, we looked for any relationships between our key variables and interest and both sex and age. Participants reported consuming pornography from 0 to 7 days per week, with an average of 1.40 days per week $(S D=1.90)$. We found a significant 
difference for sex in the number of days per week to consume pornography, $t(352)=10.73, p<$ .001 , partial $\eta^{2}=.25$. Women $(M=0.54, S D=1.24)$ reported consuming significantly less pornography than men $(M=2.43, S D=2.03)$. We also found a significant difference for sex in experienced affection, $t(352)=-3.00, p=.003$, partial $\eta^{2}=.03$. Women $(M=4.74, S D=1.02)$ reported significantly higher levels of experienced affection than men $(M=4.42, S D=0.96)$. However, there were no significant sex difference for affection deprivation, and none for any of our four outcome variables. In terms of age, we found significant correlations between age and both loneliness, $r(354)=-.13, p=.01$, and depression, $r(354)=-.11, p=.04$. However, age was not correlated with any of the other variables in the study. If any variable in a hypothesis test had significant relationships with sex or age, that demographic variable was added to the regression model (the sex variable was dummy-coded in order to be used in the analysis).

\section{Hypothesis Tests}

H1: Hypothesis 1 predicted that experienced affection is positively related to relational satisfaction and relational closeness, and inversely related to both loneliness and depression. Four regression models tested the hypothesis. We controlled for sex in all four models, and also controlled for age in the models predicting loneliness and depression. The relational satisfaction model was significant, $F(2,352)=35.60, p<.001, r^{2}=.17$. Sex $(\beta=-.13, t=-2.63, p=.009)$ and experienced affection $(\beta=.41, t=8.32, p<.001)$ were both significant predictors in the model. The relational closeness model was also significant, $F(2,352)=26.16, p<.001, r^{2}=.13$. $\operatorname{Sex}(\beta=-.12, t=-2.40, p=.017)$ and experienced affection $(\beta=.36, t=7.10, p<.001)$ were both significant predictors in the model.

Next, the loneliness model was significant, $F(3,350)=81.22, p=.001, r^{2}=.41$. Age $(\beta$ $=-.15, t=-3.51, p=.001), \operatorname{sex}(\beta=.15, t=3.44, p=.001)$ and experienced affection $(\beta=-.63, t$ 
$=-15.22, p<.001)$ were significant predictors in the model. The depression model was also significant, $F(3,350)=31.86, p=.001, r^{2}=.22$. Age $(\beta=-.13, t=-2.70, p=.007)$, $\operatorname{sex}(\beta=$ $.16, t=3.25, p=.001)$ and experienced affection $(\beta=-.45, t=-9.31, p<.001)$ were significant predictors in the model. Hypothesis 1 is supported.

H2: Hypothesis 2 predicted that affection deprivation is inversely related to relational satisfaction and relational closeness, and positively related to both loneliness and depression. Two zero-order correlations and two regression models were run to test the hypothesis. We controlled for age in the models predicting loneliness and depression. First, we ran two zeroorder correlations, finding significant correlations between affection deprivation and both relational satisfaction, $r(354)=-.60, p<.001$, and relational closeness, $r(354)=-.47, p<.001$.

Next, the loneliness model was significant, $F(2,351)=80.18, p<.001, r^{2}=.31$. Age $(\beta$ $=-.11, t=-2.53, p=.01)$ and deprivation $(\beta=.54, t=12.30, p<.001)$ were both significant predictors in the model. The depression model was also significant, $F(2,351)=43.14, p<.001$, $r^{2}=.20$. Age $(\beta=-.09, t=-1.95, p=.06)$ was nonsignificant and deprivation $(\beta=.43, t=9.00$, $p<.001)$ was a significant predictor in the model. Hypothesis 2 is supported.

H3: Hypothesis 3 predicted that pornography consumption is positively related to affection deprivation and inversely related to experienced affection. Two regression models, controlling for sex and age, tested the hypothesis. The deprivation model was nonsignificant, $F$ $(3,350)=1.65, p=.18, r^{2}=.01$. Both age $(\beta=-.02, t=-0.36, p=.72)$ and $\operatorname{sex}(\beta=.10, t=1.58$, $p=.12$ ) were nonsignificant predictors in the model, though pornography consumption was a significant predictor $(\beta=.12, t=1.97, p=.05)$. Due to the nonsignificant relationships of both age and sex within the regression model, we reran the hypothesis test as a zero-order correlation. That correlation was nonsignificant, $r(355)=.08, p=.06$. Next, the experienced affection model 
was significant, $F(3,350)=4.01, p=.008, r^{2}=.03$. Both age $(\beta=-.03, t=-0.60, p=.55)$ and $\operatorname{sex}(\beta=.09, t=1.56, p=.12)$ were nonsignificant predictors in the model, though pornography consumption was a significant predictor $(\beta=-.12, t=-2.00, p=.046)$. Hypothesis 3 is partially supported.

H4: Hypothesis 4 predicted that pornography consumption is inversely related to both relational satisfaction and closeness, and positively related to both loneliness and depression. Four regression models tested the hypothesis. We controlled for sex in all four models, and also controlled for age in the models predicting loneliness and depression. First, the satisfaction model was significant, $F(2,352)=7.58, p<.001, r^{2}=.04$. Sex $(\beta=-.18, t=-2.95, p=.003)$ was a significant predictor and weekly pornography consumption $(\beta=-.22, t=-3.66, p<.001)$ was a significant predictor in the model. Next, the closeness model was significant, $F(2,352)=$ 9.04, $p<.001, r^{2}=.05$. Sex $(\beta=-.19, t=-3.13, p=.002)$ was a significant predictor and weekly pornography consumption $(\beta=-.24, t=-4.04, p<.001)$ was a significant predictor in the model.

Next, the loneliness model was significant, $F(3,350)=5.50, p=.001, r^{2}=.05$. Age $(\beta=$ $-.10, t=-1.89, p=.06)$ was a nonsignificant predictor and both $\operatorname{sex}(\beta=.13, t=2.24, p=.03)$ and weekly pornography consumption $(\beta=.19, t=3.03, p=.003)$ were significant predictors in the model. The depression model was also significant, $F(3,350)=5.21, p=.002, r^{2}=.04$. Age $(\beta=-.09, t=-1.65, p=.10)$ was a nonsignificant predictor and both $\operatorname{sex}(\beta=.17, t=2.86, p=$ $.005)$ and weekly pornography consumption $(\beta=.18, t=2.88, p=.004)$ were significant predictors in the model. Hypothesis 4 is supported.

H5 and RQ1: The fifth hypothesis predicted that affection deprivation is positively associated with the tendency to use pornography for the purposes of loneliness reduction, escape, and the formation of parasocial relationships. The first research question asked whether affection 
deprivation correlates with the tendency to use pornography to improve life satisfaction and/or to increase sexual gratification. None of the reasons for using pornography was significantly associated with age; however, men were significantly more likely than women to use pornography to increase life satisfaction, $t(191)=2.62, p=.01, d=.39$; reduce loneliness, $t$ $(191)=2.91, p=.004, d=.44 ;$ and increase sexual gratification, $t(191)=2.23, p=.03, d=.31$. Thus, associations between those three reasons and affection deprivation were examined in hierarchical regressions controlling for sex, whereas the associations with parasocial relationships and escape were examined using zero-order correlations. All analyses were restricted to participants who reported consuming pornography on at least one day per week.

The model for loneliness reduction was significant, $F(2,190)=17.92, p<.001, R^{2}=.16$, adjusted $R^{2}=.15$. Sex $(\beta=-.21, t=-2.91, p=.004)$ and affection deprivation $(\beta=.34, t=5.12$, $p<.001)$ were both significant predictors. Moreover, affection deprivation was significantly correlated with the tendency to use pornography to form parasocial relationships, $r(191)=.22, p$ $=.001$, and for escape, $r(191)=.30, p<.001$. Hypothesis 6 is supported.

Regarding the research question, the model for life satisfaction was significant, $F(2,190)$ $=4.41, p=.013, R^{2}=.04$, adjusted $R^{2}=.03$. Sex $(\beta=-.18, t=-2.61, p=.01)$ was a significant predictor, but affection deprivation $(\beta=.09, t=1.39, p=.17)$ was not. The model for sexual gratification was significant, $F(2,190)=5.67, p=.004, R^{2}=.06$, adjusted $R^{2}=.05$. Sex $(\beta=$ $.16, t=-2.23, p=.027)$ and affection deprivation $(\beta=.18, t=2.50, p=.013)$ were both significant predictors.

H6 and RQ2: The final hypothesis predicted that pornography consumption moderates the association between affection deprivation and individual and relational wellness, and the second research question asked whether the associations between affection deprivation and 
wellness were affected by participants' stated goals for using pornography. To test hypothesis 6 , we ran four regression models to investigate the interaction between pornography consumption and affection deprivation on our four outcome variables. Although all four models were significant, the interaction terms were nonsignificant for satisfaction $(\beta=-.01, t=-0.65, p=.52)$, closeness $(\beta=.01, t=0.58, p=.56)$, and loneliness $(\beta=.01, t=0.64, p=.52)$. However, the interaction term was significant for depression $(\beta=.05, t=2.21, p=.03)$.

We probed the significant interaction effect on depression using the MODPROBE macro developed by Hayes and Matthes (2009). The probe showed that the relationship between affection deprivation and depression at low levels of weekly pornography consumption was positive and significant, $B=.25, S E B=.05, t=4.93, p<.001$. The relationship at high levels of weekly pornography consumption was still positive and stronger, $B=.43, S E B=.06, t=7.64, p$ $<.001$. Thus, as weekly pornography consumption scores rose, the positive relationship between affection deprivation and depression became stronger.

To examine RQ2, we created five interaction variables between pornography consumption and each of the stated reasons for using pornography. We then ran four different regression models on each interaction variable (a total of twenty models) to test the research question fully. None of the interaction terms was significant, although four approached significance $(p<.10)$. These included the interaction between sexual gratification and pornography consumption on relational closeness, the interaction between parasocial relationships and pornography consumption on relational satisfaction, and the interaction between escape and pornography consumption on both loneliness and depression ${ }^{1}$.

\section{Discussion}


The human need to belong - to participate in and reap the benefits of social and intimate bonds - is both pervasive and deeply engrained. Even when people have adequate levels of social inclusion in their lives - and particularly when they do not - they compensate for that need through the use of coping strategies that simulate contact and/or prompt elevations in dopamine. The present study explored one potential coping mechanism, the consumption of pornography, by assessing a series of relationships between pornography consumption, experienced affection, affection deprivation, and mental/relational wellness. The study also examined several reasons for pornography consumption, relating those to affection deprivation.

Overall, the study largely supported the initial hypotheses, showing positive correlates for experienced affection and negative correlates for affection deprivation and pornography consumption. However, the tests of the substitution claims indicate that when pornography is used as a coping mechanism, it is more maladaptive than adaptive. In this discussion, we will overview these findings, outline some theoretical and practical implications, and end with an exploration of some limitations of the study and directions for future research.

\section{Overview of Findings}

Our first predictions ( $\mathrm{H} 1$ and $\mathrm{H} 2$ ) related to the correlates of experienced affection and affection deprivation. These tests found that experienced affection is positively related to satisfaction and closeness in one's romantic relationship, and negatively associated with individual loneliness and depression, whereas affection deprivation exhibits the opposite associations. Previous studies have established both patterns (see Floyd, 2002, 2014), and these findings lend additional support. Of note are the magnitudes of the effect sizes, with correlations or beta weights ranging in absolute value from .36 to .63 , suggesting nontrivial associations between affection, affection deprivation, and these individual and relational states. 
We then predicted ( $\mathrm{H} 3$ and $\mathrm{H} 4)$ that pornography consumption is positively related to affection deprivation, depression, and loneliness, and inversely related to experienced affection, relational satisfaction, and closeness. All but one of these predictions were supported: Although the association between pornography consumption and affection deprivation was in the hypothesized direction, it was of a small magnitude and statistically nonsignificant. These findings indicate that consuming pornography is more common for people who are lonely and depressed (although not affection deprived), whereas it is less common for people who feel relationally satisfied and close to their romantic partners and who exchange high levels of affection. Of course, the causal associations — if they exist — may be bidirectional, insofar as feeling lonely or relationally unsatisfied may cause people to consume pornography and/or consuming pornography may cause people to feel lonely or unsatisfied. These possibilities await further adjudication, and we will outline some future directions for research later in this section.

We further tested the idea of the substitution effect for pornography consumption in H5 and H6. The former hypothesis predicted that, regardless of whether affection deprivation is associated with how often people consume pornography, it is positively correlated with why people use pornography. Specifically hypothesized was that affection deprivation is positively related with the tendency to use pornography for loneliness reduction, escape, and the formation of parasocial relationships, whereas RQ1 asked whether affection deprivation relates to the tendency to use pornography to improve life satisfaction and/or to increase sexual gratification. Excepting life satisfaction, all other associations with affection deprivation were significant, and the strongest associations were with loneliness reduction, escape, and parasocial relationships. These findings indicate that when people feel deficient in the amount of affection they receive, they are more likely to consume pornography for the specific purposes of reducing their 
loneliness, creating parasocial relationships with the characters depicted in pornography, and creating mental escape from their situation. These findings are directly supportive of our argument that pornography consumption is a coping mechanism for social disconnection.

Although pornography consumption is used as a coping mechanism for affection deprivation, that does not necessarily imply that it is an adaptive coping strategy. Coping strategies are adaptive only insofar as they effect reductions in the problem's negative outcomes. For instance, to the extent that affection deprivation is positively related to a negative mental health outcome such as depression, an adaptive strategy for coping with affection deprivation would lessen the magnitude of the association between affection deprivation and depression, whereas an ineffective coping strategy would have no influence on the magnitude of that association.

Our findings suggest, however, that consuming pornography to cope with affection deprivation is maladaptive, insofar as it strengthens the positive association between affection deprivation and depression. Moreover, that was true regardless of the individual goals (reducing loneliness, finding escape, etc.) participants reported for using pornography in the first place. Although pornography consumption did not moderate the associations between affection deprivation and relational satisfaction, closeness, or loneliness, its moderating effect on depression is potentially consequential, given the range of pathologies that are comorbid with depression (see Himmerich et al., 2008), up to and including suicidal ideation (Bronisch \& Wittchen, 1994).

\section{Theoretical Implications}

The current study used AET to predict that pornography consumption is partially used as a substitute for positive social connections and/or positive social communication. Specifically, 
the study used subpostulate 5a, which predicts that people will consider insufficient affection to be a limitation to their well-being and will compensate. As expected, there were consistent negative correlations between experienced affection and pornography consumption, there were multiple indirect relationships between pornography consumption and well-being through our affection variables, and there were multiple relationships between affection deprivation and the reasons for consuming pornography. In all cases, these show initial support (though obviously in a correlational fashion) that a) one reason that individuals consume pornography is due to a deficit in experienced affection and b) people will try to experience affection through the consumption of pornography, attempting to regain a sufficient amount of affection in their lives. The act of compensation discussed in subpostulate 5a, then, does not simply mean that individuals will attempt to experience more affectionate communication from friends, family members, or romantic relationships, but in any way that they deem possible.

On the other hand, in both $\mathrm{H} 3$ and $\mathrm{H} 5$, affection deprivation was not significantly correlated to pornography consumption. Thus, although individuals who were not experiencing much affection were more likely to consume pornography, this did not relate to their perception of whether they were experiencing enough affection. To some degree, this contradicts subpostulate 5a, which implies a more conscious individual reaction to a deficit of affection. AET, however, is based on evolutionary principles that discuss how humans are designed to fulfill ultimate goals of survival and procreation, regardless of a conscious decision-making process. Thus, individuals who examine AET, or subpostulate 5a in particular, might want to assess whether individuals need to be consciously aware of any deficit in order to react to that same deficit.

\section{Practical Implications}


There are several practical implications that come from the current study. First, although people are more likely to use pornography to reduce their loneliness, find escape, and form parasocial relationships when they feel affection deprived than when they do not, those findings should not be taken as prescriptive. For one, although people consume pornography for the purpose of reducing their loneliness, escaping, and forming parasocial relationships when they feel affection deprived, that does not imply that such a strategy is adaptive. Perhaps the most consequential finding to come from the current study is that, with respect to depression, consuming pornography is a maladaptive strategy for coping with depression. Although these data are cross-sectional, they imply that a longitudinal examination would reveal that consuming pornography when affection deprived exacerbates the effect of affection deprivation on depression, resulting in a net negative outcome. An analogy would be coping with loneliness by consuming large quantities of high-calorie foods, which, although it may provide pleasure in the moment, ultimately exacerbates the effect of loneliness on weight gain (see Cacioppo \& Hawkley, 2009). In addition to the fact that pornography consumption is associated with lower relational and sexual satisfaction, particularly for men (Wright, Tokanuga, Kraus, \& Klann, 2017), and with a higher propensity for sexual risk-taking (Sinković, Štulhofer, \& Božić, 2012), this finding suggests that even if consuming pornography provides sensations of social connection and escape, and temporarily increases dopamine reward, it is likely to exacerbaterather than alleviate — the longer-term problems associated with affection deprivation.

\section{Strengths, Limitations, Future Research, and Conclusion}

The use of crowdsourcing as a data collection strategy produced a sample that was more demographically diverse than that seen in much communication research (see Sheehan, 2018). We did not collect data on participants' geographic locations, but other communication studies 
collecting data via MTurk have generated samples reflecting most (if not all) U.S. states and multiple foreign countries (e.g., Floyd, 2014). This diversity is a strength for external validity and helps to ensure that the findings are not generalizeable only to college-enrolled students.

However, several limitations are relevant. First, our single-item measure of pornography consumption could have incorrectly assessed true individual levels of consumption and took no account of the forms of pornography people were consuming. Future studies might consider whether pornography consumption is a multi-dimensional construct, both in terms of amount of time spent as well as in type of pornography consumed. This might give a more complete picture of how individuals are actually consuming pornography.

In terms of our sample limitations, the mean level of pornography consumption was low, with participants consuming pornography on an average of only 1.4 days per week and only $2.8 \%$ reporting everyday consumption. The average level of affection deprivation was also relatively low, at 2.81 on a 7 -point scale. It is possible that both figures are representative of the population at large; nonetheless, replicating the study with purposive sampling to increase the average of either or both variables might provide insight into the dynamics of coping among more affection-deprived or higher pornography-using populations. We also did not ask about participants' sexual orientation. That demographic feature may be relevant insofar as some research has shown an effect of sexual orientation on pornography consumption. In a random sample of 2,381 adults in Norway, for instance, Træn and Daneback (2013) reported that women's sexual orientation (but not men's) affected their frequency of pornography consumption, and that men's sexual orientation (but not women's) affected their frequency of using pornography during sex with a romantic partner. Insofar as these effects are not culturally 
specific, they suggest that sexual orientation is a relevant factor to consider when measuring consumption.

In terms of other future directions, several possibilities arise. First, our sample consisted of individuals within romantic relationships. In terms of the question of substitution, perhaps a sample of single individuals would be even more promising as a way to see how people compensate for insufficient affection. Single individuals would not have, in theory, the accessible resources of affection given to an individual within a romantic relationship. They would thus be more likely to need to compensate and more likely to use pornography consumption due to some of the reasons we explicate in the current study (such as parasocial interaction). Second, within the context of romantic relationships, future studies should both assess any dyadic substitution effects ("Am I more likely to consume pornography when my partner is experiencing lower levels of affection?") and the differences between individual and mutual consumption of pornography ("Can pornography be used as a tool of affectionate communication within a romantic relationship?"). In both cases, these questions would allow us to better understand how experienced affection and pornography consumption affect romantic relationships.

The current study predicted a series of relationships between pornography consumption, experienced affection, affection deprivation, and mental/relational well-being for individuals within dating relationships. The study largely supported the predictions from AET that when individuals aren't experiencing enough affection, they will attempt to compensate. Affection deprivation was also significantly related to several reasons for pornography consumption, including loneliness reduction and parasocial relationships. Overall, the study shows initial evidence both that insufficient experienced affection might be one reason that individuals 
consume pornography and for the negative mental/relational effects of pornography consumption. Further work should be done to examine both claims. 


\section{References}

Åkerlind, I., \& Hörnquist, J. O. (1992). Loneliness and alcohol abuse: A review of evidences of an interplay. Social Science \& Medicine, 34, 405-414. doi: 10.1016/02779536(92)90300-F

Aron, A., Aron, E. N., \& Smollan, D. (1992). Inclusion of Other in the Self Scale and the structure of interpersonal closeness. Journal of Personality and Social Psychology, 63, 596-612. doi: 10.1037/0022-3514.63.4.596

Attwood, F. (2005). What do people do with porn? Qualitative research into the consumption, use, and experience of pornography and other sexually explicit media. Sexuality and Culture, 9, 65-86. doi: 10.1007/S12119-005-1008-7

Baek, Y. M., Bae, Y., \& Jang, H. (2013). Social and parasocial relationships on social network sites and their differential relationships with users' psychological well-being. Cyberpsychology, Behavior, and Social Networking, 16, 512-517. doi:

10.1089/cyber.2012.0510

Baumeister, R. F., \& Leary, M. R. (1995). The need to belong: Desire for interpersonal attachments as a fundamental human motivation. Psychological Bulletin, 117, 497-529. doi: $10.1037 / 0033-2909.117 .3 .497$

Beck, A. T., Steer, R. A., \& Garbin, M. G. (1988). Psychometric properties of the Beck Depression Inventory: Twenty-five years of evaluation. Clinical Psychology Review, 8, 77-100. doi: 10.1016/0272-7358(88)90050-5

Beckett, C., Maughan, B., Rutter, M., Castle, J., Colvert, E., Groothues, C., ... Sonuga-Barke, E. J. S. (2006). Do the effects of early severe deprivation on cognition persist into early 
adolescence? Findings from the English and Romanian adoptees study. Child Development, 77, 696-711. doi: 10.1111/j.1467-8624.2006.00898.x

Berinsky, A. J., Huber, G. A., \& Lenz, G. S. (2012). Evaluating online labor markets for experimental research: Amazon.com's Mechanical Turk. Political Analysis, 20, 351-368. doi: $10.1093 / \mathrm{pan} / \mathrm{mpr} 057$

Buhrmester, M., Kwang, T., \& Gosling, S. D. (2011). Amazon's Mechanical Turk a new source of inexpensive, yet high-quality, data? Perspectives on Psychological Science, 6, 3-5. doi: $10.1177 / 1745691610393980$

Blaszczynski, A., \& Nower, L. (2002). A pathways model of problem and pathological gambling. Addiction, 97, 487-499. doi: 10.1046/j.1360-0443.2002.00015.x

Boies, S. C. (2002). University students' uses of recreations to online sexual information and entertainment: Links to online and offline sexual behavior. Canadian Journal of Human Sexuality, 11(2), 77-89.

Bronisch, T., \& Wittchen, H.-U. (1994). Suicidal ideation and suicide attempts: Comorbidity with depression, anxiety disorders, and substance abuse disorder. European Archives of Psychiatry and Clinical Neuroscience, 244, 93-98. doi: 10.1007/BF02193525

Burnett, A., \& Beto, R. R. (2000). Reading romance novels: An application of parasocial relationship theory. North Dakota Journal of Speech \& Theatre, 13, 28-39.

Cacioppo, J. T., \& Hawkley, L. C. (2009). Perceived social isolation and cognition. Trends in Cognitive Sciences, 13, 447-454. doi: 10.1016/j.tics.2009.06.005

Cacioppo, J. T., \& Patrick, W. (2008). Loneliness: Human nature and the need for social connection. New York, NY: W. W. Norton. 
Carmichael, M. S., Humbert, R., Dixen, J., Palmisano, G., Greenleaf, W., \& Davidson, J. M. (1987). Plasma oxytocin increases in the human sexual response. Journal of Clinical Endocrinology \& Metabolism, 64, 27-31. doi: 10.1210/jcem-64-1-27

Carroll, J. S., Padilla-Walker, L. M., Nelson, L. J., Olson, C. D., Barry, C. M., \& Madsen, S. D. (2008). Generation XXX: Pornography acceptance and use among emerging adults. Journal of Adolescent Research, 23, 6-30. doi: 10.1177/0743558407306348

Carvalheira, A., Træen, B., \& Stulhofer, A. (2015). Masturbation and pornography use among coupled heterosexual men with decreased sexual desire: How many roles of masturbation? Journal of Sex \& Marital Therapy, 41, 626-635. doi: 10.1080/0092623X.2014.958790

Carver, C. S., Scheier, M. F., \& Weintraub, J. K. (1989). Assessing coping strategies: A theoretically based approach. Journal of Personality and Social Psychology, 56, 267-283. doi: $10.1037 / 0022-3514.56 .2 .267$

Cohen, J. (2004). Parasocial break-up from favorite television characters: The role of attachment styles and relationship intensity. Journal of Social and Personal Relationships, 21, $187-$ 202. doi: $10.1177 / 0265407504041374$

Cooper, A., Galbreath, N., \& Becker, M. A. (2004). Sex on the Internet: Furthering our understanding of men with online sexual problems. Psychology of Addictive Behaviors, 18, 223-230. doi: 10.1037/0893-164X.18.3.223

Di Chiara, G., Bassareo, V., Fenu, S., De Luca, M. A., Spina, L., Cadoni, C., ... Lecca, D. (2004). Dopamine and drug addiction: The nucleus accumbens shell connection. Neuropharmacology, 47, 227-241. doi: 10.1016/j.neuropharm.2004.06.032 
Dowling, N. A., \& Brown, M. (2010). Commonalities in the psychological factors associated with problem gambling and Internet dependence. CyberPsychology, Behavior, and Social Networking, 13, 437-441. doi: 10.1089/cyber.2009.0317

Flood, M. (2007). Exposure to pornography among youth in Australia. Journal of Sociology, 43, 45-60. doi: $10.1177 / 1440783307073934$

Floyd, K. (2002). Human affection exchange: V. Attributes of the highly affectionate. Communication Quarterly, 50, 135-154. doi: 10.1080/01463370209385653

Floyd, K. (2006). Communicating affection: Interpersonal behavior and social context. Cambridge, England: Cambridge University Press.

Floyd, K. (2014). Relational and health correlates of affection deprivation. Western Journal of Communication, 78, 383-403. doi: 10.1080/10570314.2014.927071

Floyd, K. (2016). Affection deprivation is associated with physical pain and poor sleep quality. Communication Studies, 67, 379-398. doi: 10.1080/10510974.2016.1205641

Floyd, K., Hess, J. A., Miczo, L. A., Halone, K. K., Mikkelson, A. C., \& Tusing, K. J. (2005). Human affection exchange: VIII. Further evidence of the benefits of expressed affection. Communication Quarterly, 53, 285-303. doi: 10.1080/01463370500101071

Floyd, K., \& Hesse, C. (2017). Affection deprivation is conceptually and empirically distinct from loneliness. Western Journal of Communication, 81, 446-465. doi: $10.1080 / 10570314.2016 .1263757$

Floyd, K., Hesse, C., Boren, J. P., \& Veksler, A E. (2014). Affectionate communication can suppress immunity: Trait affection predicts antibodies to latent Epstein-Barr virus. Southern Communication Journal, 79, 2-13. 
Floyd, K., Hesse, C., \& Haynes, M. T. (2007). Human affection exchange: XV. Metabolic and cardiovascular correlates of trait expressed affection. Communication Quarterly, 55, 7994. doi: $10.1080 / 01463370600998715$

Floyd, K., \& Riforgiate, S. (2008). Affectionate communication received from spouses predicts stress hormone levels in healthy adults. Communication Monographs, 75, 351-368. doi: $10.1080 / 03637750802512371$

Floyd, K., Pauley, P. M., \& Hesse, C. (2010). State and trait affectionate communication buffer adults' stress reactions. Communication Monographs, 77, 618-636. doi: $10.1080 / 03637751.2010 .498792$

Giles, D. C. (2002). Parasocial interaction: A review of the literature and a model for future research. Journal of Media Psychology, 4, 279-305. doi: 10.1207/S1532785XMEP0403_04

Grant, P. G. (2008). Food for the soul: Social and emotional origins of comfort eating in the morbidly obese. In J. Buckroyd \& S. Rother (Eds.), Psychological responses to eating disorders and obesity: Recent and innovative work (pp. 121-137). West Sussex, England: John Wiley \& Sons.

Gupta, M. A., Gupta, A. K., Schork, N. J., \& Watteel, G. N. (1995). Perceived touch deprivation and body image: Some observations among eating disordered and non-clinical subjects. Journal of Psychosomatic Research, 39, 459-464. doi: 10.1016/0022-3999(94)00146-V

Hald, G. M., \& Malamuth, N. M. (2007). Self-perceived effects of pornography consumption. Archives of Sexual Behavior, 37, 614-625. doi: 10.1007/s10508-007-9212-1

Hayes, A. F., \& Matthes, J. (2009). Computational procedures for probing interactions in OLS and logistic regression: SPSS and SAS implementations. Behavior Research Methods, 41, 
924-936. doi: 10.3758/BRM.41.3.924

Hendrick, S. S. (1988). A generic measure of relational satisfaction. Journal of Marriage and the Family, 50, 93-98. doi: 10.2307/352430

Hensley, C., Tewksbury, R., \& Wright, J. (2001). Exploring the dynamics of masturbation and consensual same-sex activity within a male maximum security prison. The Journal of Men's Studies, 10, 59-71. doi: 10.3149/jms.1001.59

Hesse, C. (2016, February). Porn and health: The mediating role of affection deprivation. Paper presented at the annual meeting of the Western States Communication Association, San Diego, CA.

Hesse, C., \& Floyd, K. (2008). Affectionate experience mediates the effects of alexithymia on mental health and interpersonal relationships. Journal of Social and Personal Relationships, 5, 793-810. doi: 10.1177/0265407508096696

Hesse, C., \& Floyd, K. (2011). Affection mediates the impact of alexithymia on relationships. Personality and Individual Differences, 50, 451-456. doi: 10.1016/j.paid.2010.11.004

Hesse, C., \& Mikkelson, A. C. (2017). Affection deprivation in romantic relationships. Communication Quarterly, 65, 20-38. doi: 10.1080/01463373.2016.1176942

Hesse, C., \& Rauscher, E.A. (2018). The relationships between doctor-patient affectionate communication and patient perceptions and outcomes. Presented at the 2018 annual conference of the Western States Communication Association, Santa Clara, CA.

Himmerich, H., Fulda, S., Linseisen, J., Seiler, H., Wolfram, G., Himmerich, S., ... Pollmächer, T. (2008). Depression, comorbidities and the TNF- $\alpha$ system. European Psychiatry, 23, 421-429. doi: 10.1016/j.eurpsy.2008.03.013

Horan, S. M., \& Booth-Butterfield, M. (2010). Investing in affection: An investigation of 
affection exchange theory and relational qualities. Communication Quarterly, 58, 394413. doi: $10.1080 / 01463373.2010 .524876$

Krüger, T. H. C., Haake, P., Hartmann, U., Schedlowski, M., \& Exton, M. S. (2002). Orgasminduced prolactin secretion: Feedback control of sexual drive. Neuroscience \& Biobehavioral Reviews, 26, 31-44. doi: 10.1016/S0149-7634(01)00036-7

Krüger, T. H. C., Hartmann, U., \& Schedlowski, M. (2005). Prolactinergic and dopaminergic mechanisms underlying sexual arousal and orgasm in humans. World Journal of Urology, 23, 130-138. doi: 10.1007/s00345-004-0496-7

Levine, M. P. (2012). Loneliness and eating disorders. Journal of Psychology, 146, 243-257. doi: $10.1080 / 00223980.2011 .606435$

Levinson, R. A., Jaccard, J., \& Beamer, L. J. (1995). Older adolescents' engagement in casual sex: Impact of risk perception and psychosocial motivations. Journal of Youth and Adolescence, 24, 349-364. doi: 10.1007/BF01537601

Löfgren-Mårtenson, L., \& Månsson, S.-A. (2009). Lust, love, and life: A qualitative study of Swedish adolescents' perceptions and experiences with pornography. Journal of Sex Research, 46, 1-12. doi: 10.1080/00224490903151374

Malamuth, N. M., \& Billings, V. (1986). The functions and effects of pornography: Sexual communications versus the feminist models in light of research findings. In J. Bryant \& D. Zillman (Eds.), Perspectives on media effects (pp. 83-108). Hillsdale, NJ: Lawrence Erlbaum Associates.

Mansson, D. H. (2013). College students' mental health and their received affection from their grandparents. Communication Research Reports, 30, 157-168. doi:

$10.1080 / 08824096.2012 .763028$ 
McBride, K. R., Reece, M., \& Sanders, S. A. (2007). Predicting negative outcomes of sexuality using the Compulsive Sexual Behavior Inventory. International Journal of Sexual Health, 19, 51-62. doi: 10.1300/J514v19n04_06

Nansel, T. R., Overpeck, M., Pilla, R. S., Ruan, J., Simons-Morton, B., \& Scheidt, P. (2001). Bullying behaviors among US youth: Prevalence and association with psychosocial adjustment. Journal of the American Medical Association, 285, 2094-2100. doi: 10.1001/jama.285.16.2094

Paolacci, G., Chandler, J., \& Ipeirotis, P. G. (2010). Running experiments on Amazon Mechanical Turk. Judgment and Decision Making, 5(5), 411-419.

Paul, B., \& Shim, J. W. (2008). Gender, sexual affect, and motivations for Internet pornography use. International Journal of Sexual Health, 3, 187-199. doi: $10.1080 / 19317610802240154$

Philaretou, A. G., Mahfouz, A. Y., \& Allen, K. R. (2005). Use of Internet pornography and men's well-being. International Journal of Men's Health, 4(2), 149-169.

Rew, L. (2000). Friends and pets as companions: Strategies for coping with loneliness among homeless youth. Journal of Child and Adolescent Psychiatric Nursing, 13, 125-132. doi: 10.1111/j.1744-6171.2000.tb00089.x

Rokach, A. (1990). Surviving and coping with loneliness. Journal of Psychology, 124, 39-54. doi: $10.1080 / 00223980.1990 .10543204$

Rook, K. S. (1984). Promoting social bonding: Strategies for helping the lonely and socially isolated. American Psychologist, 39, 1389-1407. doi: 10.1037/0003-066X.39.12.1389

Rubin, R. B., \& McHugh, M. P. (1987). Development of parasocial interaction relationships. 
Journal of Broadcasting \& Electronic Media, 31, 279-292. doi:

$10.1080 / 08838158709386664$

Russell, D. W. (1996). UCLA Loneliness Scale (Version 3): Reliability, validity, and factor structure. Journal of Personality Assessment, 66, 20-40. doi: 10.1207/s15327752jpa6601_2

Schultz, W. (2015). Neuronal reward and decision signals: From theories to data. Physiological Reviews, 95, 853-951. doi: 10.1152/physrev.00023.2014

Settersten, R. A. (2006). When nations call: How wartime military service matters for the life course and aging. Research on Aging, 28, 12-36. doi: 10.1177/0164027505281577

Sheehan, K. B. (2018). Crowdsourcing research: Data collection with Amazon's Mechanical Turk. Communication Monographs, 85, 140-156. doi: 10.1080/03637751.2017.1342043

Sinković, M., Štulhofer, A., \& Božić, J. (2012). Revising the association between pornography use and risky sexual behaviors: The role of early exposure to pornography and sexual sensation seeking. Journal of Sex Research, 50, 633-641. doi: $10.1080 / 00224499.2012 .681403$

Stein, D. J., Black, D. W., Shapira, N. A., \& Spitzer, R. L. (2001). Hypersexual disorder and preoccupation with Internet pornography. American Journal of Psychiatry, 158, 15901594. doi: 10.1176/appi.ajp.158.10.1590

Stravynski, A., \& Boyer, R. (2001). Loneliness in relation to suicide ideation and parasuicide: a population-wide study. Suicide \& Life-Threatening Behavior, 31, 32-40. doi:

10.1521/suli.31.1.32.21312 
Sun, C., Bridges, A., Johnson, J. A., \& Ezzell, M. B. (2016). Pornography and the male sexual script: An analysis of consumption and sexual relations. Archives of Sexual Behavior, 45, 983-994. doi: 10.1007/s10508-014-0391-2

Træen, B., \& Daneback, K. (2013). The use of pornography and sexual behaviour among Norwegian men and women of differing sexual orientation. Sexologies, 22, e41-e48. doi: 10.1016/j.sexol.2012.03.001

Twohig, M. P., Crosby, J. M., \& Cox, J. M. (2009). Viewing Internet pornography: For whom is it problematic, how, and why? Sexual Addiction \& Compulsivity, 16, 253-266. doi: $10.1080 / 10720160903300788$

Waller, G. (1998). Perceived control in eating disorders: Relationships with reported sexual abuse. The International Journal of Eating Disorders, 23, 213-216. doi: 10.1002/(SICI)1098-108X(199803)23:2<213::AID-EAT12>3.0.CO:2-0

Wang, Q., Fink, E. L., \& Cai, D. A. (2008). Loneliness, gender, and parasocial interaction: A uses and gratifications approach. Communication Quarterly, 56, 87-109. doi: $10.1080 / 01463370701839057$

Wiktorsson, S., Runeson, B., Skoog, I., Östling, S., \& Waern, M. (2010). Attempted suicide in the elderly: Characteristics of suicide attempters 70 years and older and a general population comparison group. The American Journal of Geriatric Psychiatry, 18, 57-67. doi: 10.1097/JGP.0b013e3181bd1c13

Willoughby, B. J., Carroll, J. S., Nelson, L. J., \& Padilla-Walker, L. M. (2014). Associations between relational sexual behaviour, pornography use, and pornography acceptance among US college students. Culture, Health, \& Sexuality, 16, 1052-1069. doi: $10.1080 / 13691058.2014 .92075$ 
Wolak, J., Mitchell, K., \& Finkelhor, D. (2007). Unwanted and wanted exposure to online pornography in a national sample of youth Internet users. Pediatrics, 119, 247-257. doi: 10.1542/peds.2006-1891

Wright, P. J., Tokanuga, R. S., Kraus, A., \& Klann, E. (2017). Pornography consumption and satisfaction: A meta-analysis. Human Communication Research, 43, 315-343. doi: $10.1111 /$ hcre. 12108

Yoder, V. C., Virden, T. B., \& Amin, K. (2005). Internet pornography and loneliness: An association? Sexual Addiction \& Compulsivity, 12, 19-44. doi: $10.1080 / 01730160590933653$ 


\section{Table 1}

Reliability Estimates, Means, Standard Deviations, and Intercorrelations for Study Variables $(N=357)$

\begin{tabular}{|c|c|c|c|c|c|c|c|c|c|c|c|c|c|c|}
\hline Variable & $\alpha$ & $M$ & $S D$ & 1 & 2 & 3 & 4 & 5 & 6 & 7 & 8 & 9 & 10 & 11 \\
\hline 2. Affection deprivation & .95 & 2.81 & 1.62 & $-.29 * *$ & -- & & & & & & & & & \\
\hline 3. Pornography consumption & -- & 1.40 & 1.90 & $-.16 * *$ & .08 & -- & & & & & & & & \\
\hline 4. Relationship satisfaction & .79 & 5.42 & 1.07 & $.39 * *$ & $-.60 * *$ & $-.13 *$ & -- & & & & & & & \\
\hline 5. Relationship closeness & -- & 5.20 & 1.52 & $.34 * *$ & $-.47 * *$ & $-.15 * *$ & $.70^{* *}$ & -- & & & & & & \\
\hline 6. Loneliness & .95 & 3.01 & 1.18 & $-.61 * *$ & $.55^{* *}$ & $.15^{* *}$ & $-.59 * *$ & $-.49 * *$ & -- & & & & & \\
\hline 7. Depression & .96 & 2.71 & 1.27 & $-.43 * *$ & $.43 * *$ & $.12 *$ & $-.49 * *$ & $-.37 * *$ & $.75^{* *}$ & -- & & & & \\
\hline 9. Use: Escape & .90 & 3.53 & 1.73 & $-.22 * *$ & $.30 * *$ & $.17^{*}$ & $-.27 * *$ & $-.20 * *$ & $.34 * *$ & $.33 * *$ & $.59 * *$ & -- & & \\
\hline 10. Use: Parasocial rels & .91 & 2.27 & 1.17 & -.09 & $.22 * *$ & $.21 * *$ & $-.18 *$ & -.08 & $.17^{*}$ & $.19 * *$ & $.59 * *$ & $.49 * *$ & -- & \\
\hline 11. Use: Life satisfaction & .90 & 3.88 & 1.25 & -.04 & .11 & $.26^{* *}$ & -.12 & -.09 & .10 & .07 & $.45^{* *}$ & $.55^{* *}$ & $.50 * *$ & -- \\
\hline 12. Use: Sexual gratification & .85 & 5.97 & 1.09 & -.04 & $.19 * *$ & $.26 * *$ & -.12 & $-.15^{*}$ & .12 & .12 & .05 & $.24 * *$ & .05 & $.34 * *$ \\
\hline
\end{tabular}


Notes. All measures employed $1-7$ scales. $* p<.05 ; * *<.01$. Probabilities are two-tailed. No alphas were calculated for pornography consumption or closeness because both were assessed with single-item measures. "Use" variables represent reported reasons for using pornography. 


\section{Endnotes}

${ }^{1}$ Due to the sheer number of models, we did not include the statistics in any tables in this manuscript. Details on these tests can be obtained by request of the first author. 